DOI: $\underline{10.20472 / E S .2017 .6 .2 .005 ~}$

\title{
CONTRIBUTION OF INCREASED LIFE EXPECTANCY TO ECONOMIC GROWTH: EVIDENCE FROM CEE COUNTRIES
}

\section{GINDRA KASNAUSKIENE, KAROL MICHNEVIC}

\begin{abstract}
:
Population aging in a backdrop of growing life expectancy can be seen in many advanced economies, but the rapid pace of these demographic changes in Central and Eastern Europe (CEE) makes it a pressing issue for the region. We investigate these two phenomena and compare results with prior research to determine their separate and combined effect on output growth in a panel regression model using Eurostat data for the period of 1996 to 2013. Our findings point to increasing life expectancy having a negative effect on the economy and the share of the population in the 30-59 age range affecting it positively. The conclusions of our research demonstrate the utility of augmenting macroeconomic models with a demographics-sensitive component and the urgency of addressing the accelerating demographic decline in the region.
\end{abstract}

\section{Keywords:}

demographics, life expectancy, population aging, economic growth, CEE countries

JEL Classification: E10, J10, J11

\section{Authors:}

GINDRA KASNAUSKIENE, Vilnius University, Lithuania, Email: gindra.kasnauskiene@ef.vu.It KAROL MICHNEVIC, Vilnius university, Lithuania, Email: kmichnewicz@yahoo.co.uk

\section{Citation:}

GINDRA KASNAUSKIENE, KAROL MICHNEVIC (2017). Contribution of increased life expectancy to economic growth: evidence from CEE countries . International Journal of Economic Sciences, Vol. $\mathrm{VI}(2)$, pp. 82-99., 10.20472/ES.2017.6.2.005 


\section{Introduction}

Since Malthus' treatise, demographic changes have been an area of interest in economic literature. Developments such as the Baby Boomer phenomenon in the USA or the Lost Decade in Japan have been extensively studied in terms of the link between the population's demographic composition and the economy as a whole. While the resulting body of theoretical literature demonstrates broad consensus over the presence of a notable effect (Jaimovich, Siu, 2009; Feyrer, 2007), empirical studies produce divergent findings. The magnitude, manifestation vectors and correct representation remain contentious subjects (Hasan et al, 2011). Variable selection issues and data availability in parts of the world contribute to methodological fragmentation.

Demographic trends in Central and Eastern Europe (CEE) are a less frequent object of study, with European studies focusing mostly on Western Europe (Lindh, Malmberg, 2009) or individual CEE countries (Smrčka, Arltova, 2012), despite the rapid pace of changes in the region. The combination of low birth rates and an increasing population share of dependents living longer is an on-going issue (Kohler et al, 2002). World Bank data shows that life expectancy at birth in the region increased by 5 years between 1996 and 2013. While growing life expectancy can be viewed as a positive development in lieu of improving quality of life, a change of this magnitude in the region has previously occurred over a period of 41 years. The possible economic implications of this process as well as regional changes in population age composition are the motivationof this study.

The goal is defined as the analysis of the effects changes in life expectancy and population age composition exert on economic growth in CEE countries. In order to achieve this goal, the authors review relevant literature, construct a theoretical model, which is then usedfor empirical analysis with methodological guidance from comparable studies, and draw conclusions, recommendations based on research results.

This paper builds upon previous studies dedicated to the effect of demographics on the economy and its components. It relies on the Life-Cycle Model (LCM) introduced by Modigliani (1966) and its recent adaptation by Bloom et al (2003). A broad comparative base is established for the empirical part, sourcing studies from regions that have experienced major demographic transformations, including the USA (Mankiw, Weil, 1989),Japan (Ohtake, Saito, 1998) and China (Gomez, Lamb, 2013).Further methodological guidance regarding age group-specific issues is taken from Poterba (2001) and Macunovich (2012).

The novelty of this paper consists of modifying LCM and applying it empirically to CEE data in order tojuxtaposethe effect of life expectancy on the economy against the effect ofstatic age group metrics jointly and in isolation. Findings are then assessed with respect to research from other regions.

Results are achieved through panel regression analysis using demographic and economic data, controlled for endogeneity and business cycle dynamics, from CEE countries over the broadest available period, 1996-2013. Regression results are then 
tested for robustness via a secondary panel of Western European countries over a longer period of time.

The authors hypothesise that changes in life expectancy and population age composition have a statistically significant effect on economic growth. Of the two variable types, life expectancy is hypothesised to be the better fit due to its dynamic nature. Both variable types are hypothesised to have overlapping effects.

Empirical results point to the statistical significance of age structure and life expectancy, analysed separately. Combining the age structure and life expectancy in a single model marginally increases explanatory power, but the benefits of increasing the number of demographic variables are mitigated by the loss of degrees of freedom in a region with restrictively short time series. The findings hold during robustness tests with out-ofsample European countries and longer time series. However, both panels feature countries experiencing the ageing phenomenon and the findings may not necessarily apply for countries with a young population. Shifts in the economic behaviour of different age groups reduce the long-term utility of the proposed approach, advising caution if used as a forecasting aid. The relatively weak effect demographic variables demonstrate on real output highlights the disconnect between strong theoretical evidence and empirical results. While further research involving multiple samples with different demographic backgrounds can potentially address this issue, limited data availability impedes progress in terms of period length and detail level.

The paper's findings suggest that life expectancy and age structure-based models perform similarly in CEE countries. The explanatory power using both approaches, close to $25 \%$, yields a result comparable to research dedicated to data from other regions and points to the utility of augmenting macroeconomic models with a demographic component. The long-term implications for the economy of CEE countries are tilted negatively due to a combination of growing life expectancy and population ageing past peak contribution years taking an increasing toll on real output.

The rest of paper is organized as follows: the next section presents a review of scientific literature on the relationship between the life expectancy, population age structure and the economy. Based on this, we develop a framework and discuss its empirical implementation in Sections 3 and 4. Section 5 presents the main results. Section 6 discusses some limitations of the study and recommendations for future research. Section 7lists conclusions.

\section{Demographic Changes and Real Output Growth in Literature}

The post-war generation in the US, often referred to as Baby Boomers, has been of interest to economists for some time now. Mankiw, Weil (1989) present one of the earliest forays in the field. While their concern is mainly with the housing market, the implications of a large capital-endowed cohort exiting from the workforce are significant for the whole economy.

Research in the connection between the population's age structure and the economy is closely related to life-cycle behaviour, formalised by Modigliani (1966) in the Life-Cycle Model (LCM). In essence, age is treated as a behavioural anchor, with young, middle- 
aged and retired people having a different effect on the economy through savings and consumption.Later studies present different ways of separating said groups, but follow the same pattern (Bergatino, 1998; Bloom et al, 2003; Settersten Jr., Mayer, 1997; Attanasioet al, 1999; Hasan et al, 2011). Feyrer (2007) attributes $25 \%$ of differences in output in OECD countries over the period of 1960-1990 to differences in demographic structure. Gomez, Hernandez De Cos (2008), Krueger, Fernandez-Villaverde (2007) cite explanatory power of the ageing phenomenon worldwide and in the US at over $50 \%$ while projections by Guest, McDonald (2007), Jaimovich, Siu (2009) put it at 33\%. Bloom, Williamson (1996), Choudhry, Elhorst (2010) and Pryor (2003) consider the relative size of the workforce in the population as the source of the differences in the strength of the effect. Börsch-Supanet al (2006) conclude the significance of demographics in a European setting, namely, France, Germany and Italy. Floden (2003) highlights differences in aging behaviours in different regions. This is further touched upon by Choudhry, Elhorst (2010) in a panel of three countries: China, India, Pakistan. Results put the explanatory power, respectively, at 46\%, 39\%, 25\%, with a smaller effect in predominantly youthful populations. Marattin, Salotti (2011) note that the effect is more pronounced in developed countries. Attanasioet al (1999) offer an explanation that demographic effects, albeit slow to manifest in data, evolve over time. Higgins (1998) concludes that significance of the effect is to increase as ageing accelerates. In this respect, Europe's population dynamics make for a sensitive environment for the negative effects of ageing to manifest (Floden, 2003). Kenc, Sayan (2001) make the case for open economies experiencing spillover effects, making changes in real output caused by demographic trends difficult to isolate for neighbouring countries.

Historical demographic trends show that they can have a positive effect on the economy. The Asian economic miracle is one such example, associated with a transition to a lower birth rate and higher life expectancy, resulting in a so-called "demographic dividend" (Cai, 2010; Gomez, Lamb 2013; Bloom, Williamson, 1996). A growing working-age share of the population leads to faster output expansion, with the eventuality of Asian economies converging with a value of GDP per capita comparable to that of the USA (Ha, Lee, 2016), a positive demographic transition leading up to an economic transition (Cervellati, Sunder, 2015; Yang, 2014). Hu (1995) points to the continuous positive effect of ageing on the economy, provided it is not distorted by policy. Gomez, Lamb (2013) focus on demographic changes in China, crediting a growing of the relative share of age groups in the "prime" 30-54 years range and adding the possibility for this range to extend.

Japan-oriented studies point to the country's evolution from rapid output growth in the 1980 's to a lost decade and a corresponding change in its age structure. Ohtake, Saito (1998) claim that $50 \%$ of GDP expansion in the 1980's can be attributed to demographics. However, the rapid rise in the share of working-age population proved unsustainable in later generations (Dekle, 2000; Mankiw, Weil, 1989). Bloom, Williamson (1996) warn about the economic instability caused by rapid changes in the population pyramid, forcing the economy to incur transformation costs, evident in depressed output growth rates. While Chomik, Piggott (2015) and Macunovich (2012) argue that Japan is a prologue to developments in other countries, Floden (2003) and 
Oliver (2015) show conceptual and empirical evidence to the contrary. Razin, Sadka (2007) highlight the issue of divergent social policy as a factor.

European research dedicated to population ageing exemplifies the phenomenon's importance across the region. Muysken, Ziesemer (2013) point out the negative effect of ageing on GDP in the Netherlands. Hondroyiannis, Papapetrou (2000) predict an economic downturn in Greece bourn from low fertility and increasing dependency ratios. Smrčka, Arltova (2012) reach a similar conclusion regarding the Czech Republic. Blake, Mayhew (2006) question the sustainability of the UK economy in an ageing, low-fertility scenario. Lindh, Malmberg (2009) determine a hump-shaped dependency of GDP growth on different age groups, associating stagnation with ageing in EU15.

The shape of the dependency is also referred to as an inverted $U$, representing net positive effects of age groups in the middle and depressive effects of children and retirees. A number of studies support the conclusions stemming from LCM and rely on support and dependency ratios. Ha, Lee (2016), Gomez, Lamb (2013), Guest, McDonald (2007), Tyers, Shi (2007), Pryor (2003) focus on the positive effect of the support ratio. Choudhry (2010), Hondroyiannis (2000) determine the negative effect of age groups caught in the dependency ratio. Going into further detail, Rojas (2005) distinguishes different age groups within the support ratio as having a different effect on output due to imperfect labour substitution. The addition of a population structure increases the model's predictive power more than the inclusion of dependency or support ratios. Poterba (2001) suggests the notion of "prime saving years" in the 40-64 years range, but admits reduced explanatory power of the said range, compared to theoretical calculations, when working with empirical data. Goyal (2004) shifts the groups with the highest positive effect to the 45-64 range, calling them "net contributors", reiterating Poterba's (2001) conclusion on predictive power. Gomez, Lamb (2013) suggest a 30-54 "prime age" range, while Attanasioet al (1999) state the peak years are between 38 and 41. Macunovich (2012) adds the utility of the shrinking share of the population in the 15-24 years age range as a leading indicator of economic downturns.

The effect of ageing on real output growth is not universally recognised. The question arises mainly in empirical literature (Hasan et al, 2011) and it can be separated into two groups: mitigation and proxification. In the first case, natural checks and balances or active policy counter the effect of ageing, preventing it from manifesting in the real economy, while the second supplants ageing as a proxy for a different process.

Starting with mitigation, Muyskenet al (2013), Rowthorn (2008), Tyers (2007) and Zimmerman (2005) point to migration trends and their long-term effect on real output. Merette, Georges (2010) also refer to globalisation reinforcing the spillover effect conceptualised by Kenc, Sayan (2001). Kinsella, Philips (2005) take note of changing behavioural patterns of retirees, exemplified by Cigno (1993) in the notion of intergenerational transfers and altruism: rather than spend all of the accumulated capital in retirement, retirees transfer a part of their wealth to their offspring and in doing so compensate the loss of productivity after entering retirement. Silivertovset al (2011), Smrčka (2012) and Tabata (2005) add economy specialisation, referring to business sectors that benefit or experience losses from the increase in the share of old people in 
the population. With specialisation in mind, ageing may exert a positive, negative or zero cumulative effect on real output.

Policy is another source of mitigation. Börsch-Supanet al (2006), Heijdraet al (2009) and Tyers (2007) detail various forms of government response to ageing, from managing welfare redistribution to pension reform. Hu (1995), Echevarria, Iza (2006) denote the issue of policy altering behaviour through retirement benefits. Heijdraet al (2009), Razin (2007) warn about the limited practical effect of policy, considering the government's budgetary constraints and political alignment, yet its propensity to take action, Disney (2007) explains, can produce a lasting effect and change the shape of the population pyramid.

Age acts as an accessible behavioural anchor, which is assumed to be fixed. Increasing life expectancy challenges this assumption by shifting lifecycle phases in time. Minimum retirement age hikes and advances in healthcare throughout Europe facilitate people working and living longer. This trend also changes the concept of young and old, as detailed by Kinsella et al (2005). Tyers (2007) points out the emergence of the old age participation ratio as a positive result of growing life expectancy, which age does not explain. Gonzalez-Eiras, Niepelt (2012) study changing life expectancy rather than age as an explanatory variable for economic growth. Gomez, Lamb (2013) explain that changes in life expectancy result in the fluidity of the "prime age", concluding that this stage is prolonged as life expectancy increases. Conversely, Chakraborty (2004) claims that short life expectancy, a frequent occurrence in a young society, is a negative factor for the economy, as human capital is not sufficiently accumulated. Tabata (2005) challenges this conclusion by focusing on healthcare costs in populations with greater life expectancy and refers to additional redistribution possibilities in a young society. While these two claims are difficult to reconcile in linear terms, Echevarria (2004) claims that life expectancy's effect on real output has an inverted $U$ pattern, which contains a top threshold that is between 45 and 50 years. This is confirmed by Eggleston (2012) and corresponds to peak contribution ages detailed by Poterba (2001) and Goyal (2004).

Life expectancy is not without flaws when it comes to drawing conclusions about its effect on output growth. Katz (2000) and Settersten Jr et al (1997) conclude that it is what people do that matters and their decisions to partake in economic activity are not necessarily rooted in statistical metrics. Gollier, Zeckhauser (2002) put the notion of horizon length driven by an individual's expectations, albeit these are difficult to obtain in practice. The existence of a government is another issue for life expectancy as an effective variable, as growing live expectancy prompts a higher retirement age, which extends the $U$ pattern and preserves the status quo over a longer time span (Bloom et al, 2003). As such, life expectancy theoretically addresses the inflexibility of age, but its effect remains susceptible to the same mitigation factors. In practice, it does not necessarily reflect individual horizon lengths and its explanatory power may be inferior to that of age.

The next section lays out the methodology to test the viability of age and life expectancy as components in a regression model detailing real output growth. 


\section{The Theoretical Framework}

The authors rely on Modigliani's (1966) Life-Cycle Model and its expansion by Bloom et al (2003) to studyeffect of demographic age variables and life expectancy on the economy. The proposed model adapts the individual's lifetime consumption approach by introducing a term-dependent feedback coefficient, allowing for endogenous lifespan growth in an economy characterised by productivity growth. For simplicity, the model ignores changes in fertility and household living arrangements and precludes going into debt. By focusing on the individual's problem, the model avoids the issue of population growth.

Consider an individual's real lifetime consumption $(c)$, which consists of inherited wealth $\left(w_{0}\right)$, lifetime earnings $(y)$ and bequests $(w)$.

$c=w_{0}+y-w$

Then, the individual's mean annual consumption $(\bar{c})$ is equal to lifetime consumption divided by their lifespan $(T)$, which is known.

$\bar{c}=\frac{w_{0}+y-w}{T}$

Adding the assumption that the individual's annual income is growing at a rate of $g$ ( $g=\frac{y_{t}}{y_{t-1}}$ ), we may calculate the individual's consumption at period $t$, which corresponds to a period in the lifespan as opposed to a particular date, as follows:

$$
c_{t}=\frac{w_{0}+\frac{y(1-g)}{1-g^{t}} g^{t}-w}{T}
$$

The model is supplemented with the assumption that income growth affects the original lifespan due to advances in health and social care through the feedback coefficient $a_{t}$, which, in turn, determines the steepness of the slope of the annual consumption function.The coefficient allows the inclusion of the retirement period in the lifespan variable.

$c_{t}=\frac{w_{0}+\frac{y(1-g)}{1-g^{t}} g^{t}-w}{\left(a_{t} g\right)^{t} T}$

After substituting $y$ with $y_{t-1}$, we get:

$c_{t}=\frac{w_{0}+g y_{t-1}-w}{\left(a_{t} g\right)^{t} T}$ 
Since consumption is defined as total consumption (including savings) and not just consumption expenditures, we may substitute $c_{t}$ for $y_{t}$ and $w$ for $w_{0}$.

$$
y_{t}=\frac{g y_{t-1}}{\left(a_{t} g\right)^{t} T}
$$

Solving for $g$, we get:

$$
g=\frac{1}{a_{t} \sqrt[t]{T}}
$$

Ergo, the effect of demographic variables in the modelled economy on the micro levelis defined by the individual's lifespan, the current period in their lifespan and the feedback coefficient.Because $\sqrt[t]{T}>1$ for $t, T>0, a_{t}<1$ during periods of income growth and $a_{t} \geq 1$ during recessions. The feedback coefficient allows for a retirement period dependent on the individual's utility function.

By broadening the model to a population, which consists of individuals standing at different periodsin their lifespan, we obtainaggregate annual real income growth values for each period, which can then be analysed on the macro level.It is worth noting that this aggregation produces one value of $g$ for all individuals, who are at period $t$ of their lifespan $T$. If we denote the size of this cohort relative to the population as $\beta_{t}$, the aggregate annual growth rate for all cohorts, $G$, would be the weighted average of income growth in each cohort.

$$
G=\sum_{t=1}^{T} \beta_{t} g_{t}
$$

The model's application has several shortcomings regarding the income growth rate, its feedback coefficientand the individual's lifespan. In an empirical scenario, business cycle dynamics and exogenous shocks alter the income growth rate in the short run, necessitating additional control variables. The feedback coefficient's inherent endogeneity poses another risk, as the effect of demographic age variables can be overstated, absent controls for health and social care. Lastly, the exact length of the individual's lifespan and, consequently, the current period of their lifespan are unknowable in practice, substituting them with expected values. The selection of appropriate proxy variables is still a source of debate, as demonstrated in the literature review.

\section{Establishing the Empirical Scope}

Having determined the point of contention that is the efficacy of using age and life expectancy to gauge the effect of demographic trends on real output growth and derived a theoretical model detailing the connection of demographic age variables to the economy, we move on to empirical research design. This section details the procedures for data analysis, model selection and robustness checking. 
Since Central and Eastern Europe is the paper's focus, factored by the rapid population ageing in the region in the context of growing life expectancy as well as a dearth of comparable regional studies, we use Eurostat as the primary source of quantitative data. The geography of Central and Eastern Europe, for the purpose of this paper, is defined as the following list of countries traditionally assigned to the region: Austria, Bulgaria, Croatia, Czech Republic, Estonia, Hungary, Latvia, Lithuania, Poland, Romania, Slovakia, Slovenia. We take individual countries to form a panel using methodological guidance from Lindh et al (2009), Cervellatiet al (2015), Plumperet al (2005). Minor differences between countries are addressed through the inclusion of fixed cross-section effects, prior tested with the redundant fixed effects test, resulting in each country having a different intercept term.

The length of the time series is determined by data availability, spanning over 18 years from 1996 to 2013. While a period of at least 25 years is preferred as per Bloom et al (1996), Lindh et al (2009), the magnitude of changes in CEE countries makes robust estimation with shorter time series possible due to the increase of significance, per Higgins (1998).According to World Bank data, over the selected period the mean increase in life expectancy at birth in CEE countries has been 5 years. The most recent change of this magnitude took 34 years (1979-2013) in the USA and 26 years (19892013) in Japan. Previously, this 5-year change has taken 41 years (1960-2001) in CEE countries.

The dependent variable is the logarithmic, differenced value of real output per capita, ie. the rate of change of real output growth. The long-term focus makes the case for the usage of annual rather than quarterly data, with an adjustment for the outlying 2009 crisis. While the annual percentage change of real output is more common in studies of this type, its use requires remedial measures due to non-stationarity and base issues.

A secondary adjustment of the dependent variable is done by eliminating the effect of advances in healthcare and social services in monetary terms. This is done to avoid the endogeneity issue through the feedback coefficient, as laid out in the previous section.

Moreover, to control for business cycle effects, the lagged dependent variable is included on the right-hand side of the regression.

For the demographic variables, our selection is motivated by structure. Ratios, such as the old-age dependency ratio are less demanding in terms of degrees of freedom, but they withhold information about the labour force by aggregating it in the support ratio. We propose dividing the population pyramid into 10-year age intervals and measuring the values of the independent variables in each age group directly, starting with ages 10-19 and ending with 80 and over, eight groups in total. The division allows for sufficient degrees of freedom while retaining the information to compare the findings to prior research. Excluding the first group is a necessity to avoid perfect multicollinearity. The first group is selected due to the ageing and life expectancy trends manifesting on the right-hand side of the time scale.

Macunovich (2012) and Arnott (2012) criticise this approach as ad hoc and suggest force-fitting the age structure into an nth degree polynomial. Their alternative, however, 
produces inefficient estimates due to multicollinearity and assumes a smooth transition between age groups, precluding the hump shape obtained by Attanasioet al (1999) and Lindh (2009).

Each ten-year age group takes the form of the share it has in the population of the particular country in the particular year. As such, the values range from nought to one.

Life expectancy of each ten-year age group is calculated as the mean of life expectancies for each year in the group, measured in years, divided by 100 for comparison with age group shares. This yields eight values of life expectancy per country per year.

The equations for each panel regression expand equation (8) the following way:

$$
g_{t, c}=a_{c}+\sum_{i=1}^{8} \gamma_{t-1, c, i} x_{t-1, c, i}+g_{t-1, c}+\ldots+g_{t-k, c}+\varepsilon_{t, c}
$$

$g_{t, c}$ - the logarithmic, differenced value of real output per capita at period $t$ of country $c$

$a_{c} \quad$ - intercept term of country $c$

$\gamma_{t-1, c, i}$ - the coefficient of age group $i$ at period $t-1$ of country $c$

$x_{t-1, c, i}$ - the share age group $i$ takes up in the population in country $c$ at period

$t-1$

Note that equation (9) deals with the share each age group has in a specific country's population during a specific period. By substituting these shares, denoted as $x$, with corresponding life expectancies, denoted as $p$, and their coefficients $\varphi$, we get (10).

$$
g_{t, c}=a_{c}+\sum_{i=1}^{8} \varphi_{t-1, c, i} p_{t-1, c, i}+g_{t-1, c}+\ldots+g_{t-k, c}+\varepsilon_{t, c}
$$

Consequently, the model detailing the combined effect of age shares and life expectancy is as follows (3):

$$
g_{t, c}=a+\sum_{i=1}^{8} \gamma_{t-1, c, i} x_{t-1, c, i}+\sum_{i=1}^{8} \varphi_{t-1, c, i} p_{t-1, c, i}+g_{t-1, c}+\ldots+g_{t-k, c}+\varepsilon_{t, c}
$$

Upon calculation of (9), (10) and (11), we verify the findings by rerunning the equations on data from Western European countries that do not share a land border with the main panel thus avoiding spillover effects while following guidance by Macunovich (2012) 
about comparing countries with similar population structures. The secondary panel is subject to data availability, with the period starting from 1981, and includes Belgium, Denmark, France, Netherlands, United Kingdom, Spain, resulting in a panel of similar size.

\section{Empirical Findings}

Using the methodology described in the previous section, we construct three models. Model A features age structure statistics for the population of each country in the panel. Model B uses the respective country's life expectancy values. Model A+B joins the statistically significant variables of both models to determine the joint explanatory power of their variables.

Model A, depicted in Table 1, determines a statistically significant effect, as defined by an F-stat of 7.79. It explains $43 \%$ of variance of real output's rate of change $(24 \%$ without the lagged dependent variable), which is in line with figures obtained by Arnott (2012), Choudhry et al (2010) and Feyrer (2007). Despite mentions of the importance of population structure, Model A features only three age groups, ages 30-39, 40-49, 5059 , with coefficients for the other groups being statistically insignificant at a $10 \%$ significance level.

The statistically significant variables, however, confirm the presence of a peak or hump shape, as defined by Lindh et al (2009) and the placement of that peak, between 40 and 49, is in line with Attanasio et al (1999). However, the range is 10 years below the peak contribution age defined byGoyal (2004) and Poterba (2001). The shape of the underlying curve does not contradict LCM assumptions.

Model B also measures a statistically significant effect, F-stat of 9.7 , explaining $46 \%$ of variance ( $28 \%$ without the lagged dependent variable). It features significant coefficients of life expectancies for different age groups and confirms Macunovich (2012) claim about the importance of the youth. Ages 20-29 fall between the first two LCM stages, highlighting the possible establishment of horizon length, as defined by Gollier (2002), for future undertakings and follows the logic of the theoretical model: the increasing life expectancy dampens growth.The statistically significant variables demonstrate the limited success of mitigation through policy, mimicking the conclusions derived from Model A. Contrary to the promise of flexibility, Model B does not appear to hold significantly more promise in termsof explanatory power thanmodel A. However, test results point to adherence to the theoretical framework.

The joint Model $A+B$ sums up the statistically significant variables of both models. TheF value of 9.93and improvement to the adjusted R-square, up to 0.51 ( 0.37 without the lagged dependent variable) in Model $A+B$, demonstrates that life age structure and life expectancy explain a similar, partially overlapping portion of the rate of change of real output growth. The combination of the two variable groups decreases the degrees of freedom, an issue with limited time series. This suggests partial interchangeability between variable types when analysing the effect of age trends on real output, in lieu of the positive link between ageing and growing life expectancy. In practice, however, this is likely to have limited use, as life expectancy data is collected for a shorter time period 
than population age structure. The age groups involved in Model $A+B$ also point to the possibility of different transmission mechanisms at work, leading to a coincidental overlap due to both life expectancy and age increasing during the analysed period.

Table 1. Statistically significant model variables, coefficient values and test statistics

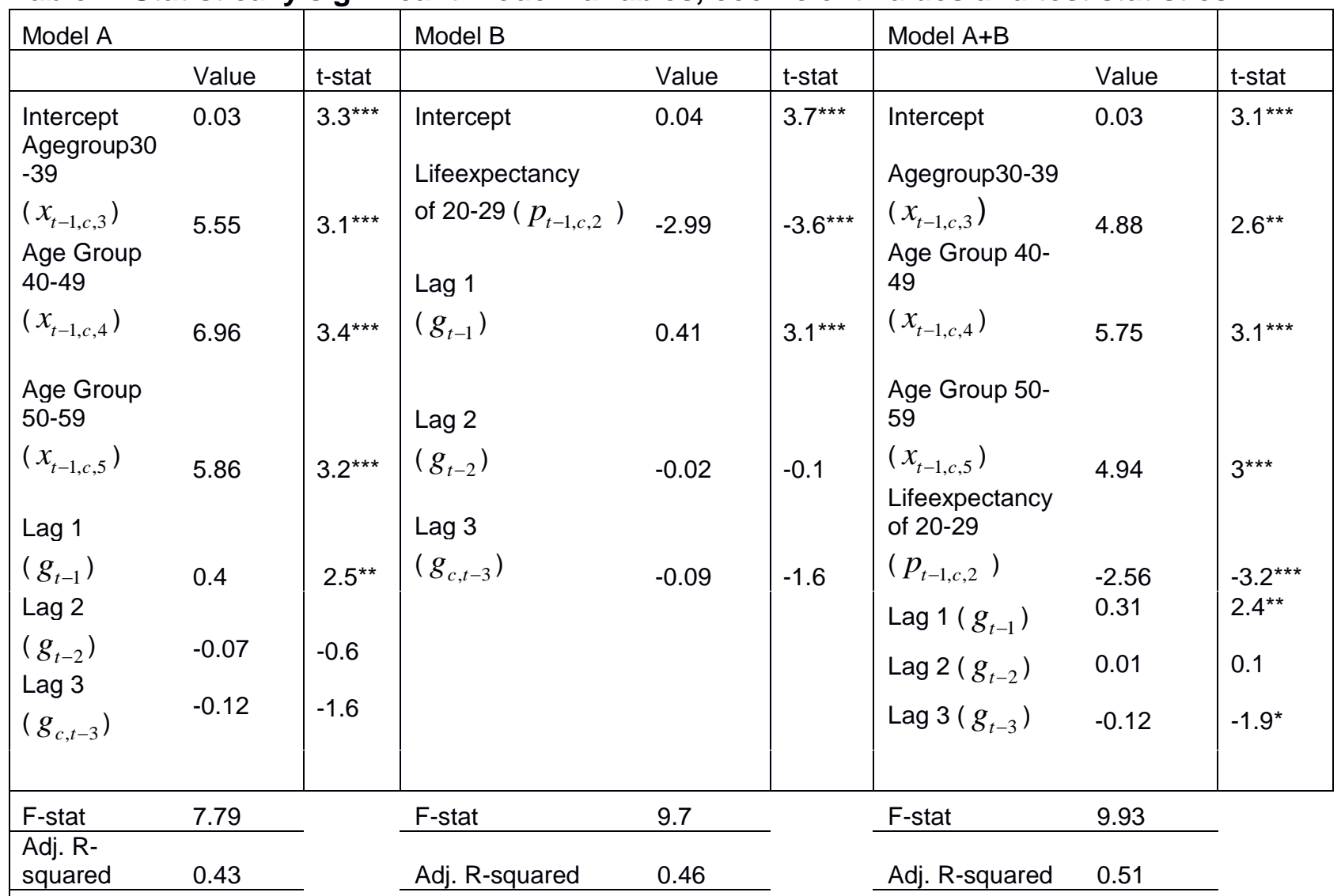

${ }^{* * *}$ Statisticallysignificant at $1 \%$ significancelevel

** Statisticallysignificant at $5 \%$ significancelevel

*Statisticallysignificant at $10 \%$ significancelevel

Source: owncalculationsbasedonEurostat data

We verify the above findings by running a secondary series of models for a panel of Western European countries. The test statistics are available in Table 2, the corresponding test models labelled as Test $A$, Test $B$ and Test $A+B$. All three models are statistically significant at a $1 \%$ significance level and perform similarly to models from first sample. While the second sample contains different countries, their populations are experiencing the same demographic trends as the first sample and data limitations cause for partial period overlap, which reduces the power of the test. It is also worth noting that ageing and life expectancy gains have accelerated in countries from both samples over the final 10 years in the period, affecting test values, while sociopolitical transformations at the start of the period in the second sample, such as the collapse of the Soviet Union, present another divide in data dynamics. Fragmentation is to be considered in both time and geography. 
Table 2. Robustness test statistics

\begin{tabular}{|l|l|l|l|}
\hline & Test A & Test B & Test A+B \\
\hline F-stat & 9.5 & 10.7 & 9.22 \\
\hline Adj. R-squared & 0.36 & 0.34 & 0.37 \\
\hline
\end{tabular}

Source: owncalculationsbasedonEurostat data

Empirical results point to the utility of adding shares of different age groups in the population or life expectancy values as a means of improving a macroeconomic model's explanatory power, but the inclusion of both variable groups is not recommended due to the overlapping effects. The life expectancy model explains a marginally higher portion of variance in real output dynamics. Both models appear in line with the theoretical framework, LCT stipulations. Adherence to results achieved in prior empirical studies also shows that the strength of the connection between the sizes of different age groups in the population is similar in a number of samples and periods, which is also demonstrated in the secondary sample of Western European countries.

Research results do not permit rejection of the formulated hypotheses, as both models demonstrate a statistically significant effect on real output, of which the life expectancy model performs marginally better, and the overlapping effect is noted. Despite practical application putting both variable groups on a similar level, the life expectancy model is preferred due to its adherence to theoretical stipulations and flexibility as a behavioural anchor.

\section{Limitations and Recommendations for Future Research}

Life expectancy is cited as a theoretical solution to the static nature of age, but our results highlight the disconnect between theory and empirical evidence in that both approaches have similar explanatory power. The criticism of age groups acting as a proxy, however, necessitates discovery of alternative variables to represent the ageing effect in lieu of LCM assumptions.

Furthermore, the findings may not necessarily apply to countries with a different population structure: predominantly young or transitioning towards lower life expectancy. Obtaining empirical data with such parameters to broaden the model's spectrum may prove problematic due to conditions required to instil such changes in a population. The implications of cultural differences and intergenerational relationships may yield conclusions contrary to those applicable in Central and Eastern Europe, prompting comparable studies in other regions.

Differences in statistically significant variables in the life expectancy and age group models point to the possibility of seemingly overlapping, yet different transmission mechanisms. Applying the model to another time series, where growing life expectancy is not accompanied by receding birth rates, may confirm the practical distinction between using life expectancy and age groups.

Data availability is the biggest hurdle for analysing the slow development of demographic trends, as it limits the detail level of the study while competing reporting 
standards make comparisons in broader panels less accurate. Hence, the introduction of reduced-form representations, such as peak age ranges, may prove more effective than the analysis of the population structure as a whole.

\section{Conclusions}

Population ageing in a backdrop of growing life expectancy is an issue not unique to Central and Eastern Europe, but the rapid pace of these demographic changes in the region is a cause for concern. The demographic trend has proven its persistence in spite of mitigating factors, such as globalisation and government policy. The ability to gauge the effect of ageing and growing life expectancy on real output is a necessary step to address the issue.

Prior research about the effect of ageing on real output focuses on three closely-related topics: the magnitude of the effect, vectors of its transmission and the effect's correct representation. The first helps to determine the viability of including demographic variables in a macroeconomic model. Empirical studies place the variables' explanatory power in the range of a quarter to a third of real output variance, with a body of literature dedicated to its non-linear nature, stemming from the Life-Cycle Model. The second defines the parts of the population, through which the effect manifests itself, be it retirees or those in their prime. Since neither concept is bound to a specific age, research offers a range of figures and representation methods. The latter can be summed up as a division between broad ratios, such as the old-age dependency ratio, and narrower variables pertaining to population structure. The ongoing debate involves the competing representation of the effect via age groups, which are fixed, and life expectancy, which is changing.

Our input is not limited to either approach, as we attempt to juxtapose their results empirically. While both age groups and life expectancy appear to have a statistically significant effect on real output in CEE countries, explaining $28 \%$ and $24 \%$ of variance, respectively, their joint effect appears to overlap. The model describing their joint effect exhibits only a marginal increase in explanatory power. Relationships determined in the primary panel are also present in the secondary panel with Western European data and a longer time series.

Similar explanatory power, when studied in isolation, and overlapping effect, taken jointly, point to interchangeability of life expectancy and age group variables for the purpose of studying their influence on real output growth. However, the model pertaining to life expectancy is preferable due to its adherence to the theoretical framework and slightly better fit with a lower degrees of freedom requirement. Considering the above, none of the hypotheses laid out in the introduction are rejected.

The life expectancy model demonstrates the importance of the 20-29 age group, coinciding withtheoretical LCM stipulations as an inflection point andestablishment of a horizon length for future undertakings. The negative effect that an increase of life expectancy in this group exerts on real output growth is in line with the derived framework and points to expectations of longer retirement. As such, the negative effect takes place early in the age group curve and is not directly influenced by life 
expectancies in post-retirement groups. Ongoing advances in health and social care, as experienced in other developed countries, exacerbate the effect of life expectancy on the economy, absent a proportional increase in retirement age or real lifetime earnings.

Statistically significant age groups in the age group model follow the "peak" or "prime" ages as perAttanasioet al (1999), Poterba (2001) and Goyal (2004). The 30-59 range, peaking at 40-49 is also in line with theoretical LCM assumptions regarding the inverted $U$ pattern of each age group's effect on real output growth. The model's explanatory power, statistically significant variables and their positive coefficients point to phenomena discovered in Japan and the USA taking place in CEE countries. Due to the absence of age groups of dependents, the negative effect of demographic change manifests in the reduction of the relative share the 30-59 age range has in the population. Maintaining a high population share in this group is a compounding challenge due to low birth rates across the region reducing the inflow at the start of the range.

Albeit the life expectancy model and the age group model explain an overlapping share of variance, the age ranges involved (20-29 for life expectancy, 30-59 for age groups) suggest that different transmission mechanisms could be involved in each case. A combination of societal ageing, low birth rates and growing life expectancy makes it challenging to separate the potential transmission mechanisms in empirical data.

\section{References}

Arnott, R. D.; Chaves, D. B. (2012). Demographic Changes, Financial Markets, and the Economy. Financial Analyst Journal,Vol. 68, p. 23-45.

Attanasio, O. P.; Banks, J.; Meghir C.; Weber, G. (1999). Humps and Bumps in Lifetime Consumption. Journal of Business and Economic Statistics. Vol. 17, no. 1, p. 22-35.

Bergatino, S. M. (1998). Life Cycle Investment Behavior, Demographics, and Asset Prices: dissertation. MIT, Department of Economics, p. 37-59, 120-126.

Blake, D.; Mayhew, L. (2006). On the Sustainability of the UK State Pension System in the Light of Population Ageing and Declining Fertility. The Economic Journal. Vol. 116, p. 286-305.

Bloom, D. E.; Canning, D.; Graham, B. (2003). Longevity and Life-cycle Savings. Scandinavian Journal of Economics. Vol. 105, no. 3, p. 319-338.

Bloom, D. E.; Williamson, J. G. (1996). Demographic transitions and economic miracles in emerging Asia. World Bank Economic Review. Vol 12, no. 3, p. 419-455.

Börsch-Supan, A.; Ludwig, A.; Winter, J. (2006). Ageing, Pension Reform and Capital Flows: A MultiCountry Simulation Model. Economica. Vol. 73, p. 625-658.

Cai, F. (2010). Demographic transition, demographic dividend, and Lewis turning point in China. China Economic Journal. Vol. 3, no. 2, p. 107-191.

Cervellati, M.; Sunder, U. (2015). The economic and demographic transition, mortality, and comparative development. American Economic Journal: Macroeconomics. Vol. 7, no. 3, p. 189-225.

Chakraborty, S. (2004). Endogenous lifetime and economic growth. Journal of Economic Theory. Vol 116, p. 119-137.

Chomik, R.; Piggott, J. (2015). Population Ageing and Social Security in Asia. Asian Economic Policy Review. Vol. 10, p. 199-222.

Choudhry, M. T.; Elhorst, J. P. (2010). Demographic transition and economic growth in China, India and Pakistan. Economic Systems. Vol 34, p. 218-236.

Cigno, A. (1993). Intergenerational transfers without altruism. Family, market and state. European Journal of Political Economy. Vol. 9, no. 4, p. 505-518. 
Dekle, R. (2000). Demographic destiny, per-capita consumption, and the Japanese saving-investment balance. Oxford Review of Economic Policy. Vol. 16, no. 2, p. 46-60.

Disney, R. (2007). Population ageing and the size of the welfare state: Is there a puzzle to explain? European Journal of Political Economy. Vol. 23, p. 542-553.

Echevarria, C., A. (2004). Life Expectancy, Schooling Time, Retirement, And Growth. Economic Inquiry. Vol. 42, no. 4, p. 602-617.

Echevarria, C., A.; Iza, A. (2006). Life Expectancy, human capital, social security and growth. Journal of Public Economics. Vol. 90, p. 2323-2349.

Eggleston, K. N. (2012). The new demographic transition: Most gains in life expectancy now realized late in life. Journal of Economic Perspectives. Vol. 26, no. 3, p. 137-156.

Feyrer, J. (2007). Demographics and Productivity. The Review of Economics and Statistics. Vol. 89, no. 1, p. 100-109.

Floden, M. (2003). Public Saving and Policy Coordination in Aging Economies. Scandinavian Journal of Economics. Vol. 105, no. 3, p. 379-400.

GDP and main components - volumes. [online] Eurostat. Available at: http://appsso.eurostat.ec.europa.eu/nui/show.do?dataset=nama_gdp_k\&lang=en [Accessed on 12 Jan. 2016]

Goyal, A. (2004). Demographics, Stock Market Flows, and Stock Returns. Journal of Financial and Quantitative Analysis. Vol. 39, no. 1, p. 115-142.

Gollier, C.; Zeckhauser, R. J. (2002). Horizon Length And Portfolio Risk. Journal of Risk and Uncertainty. Vol. 24, no. 3, p. 195-212.

Gomez, R.; Hernandez De Cos, P. (2008). The importance of being mature: The effect of demographic maturation on global per capita GDP. Journal of Population Economics. Vol. 21, no. 3, p. 589-608.

Gomez, R.; Lamb, D. (2013). Demographic Origins of the Great Recession: Implications for China. China \& World Economy. Vol. 21, no. 2, p. 97-118.

Gonzalez-Eiras, M. Niepelt, D. (2012). Ageing, government budgets, retirement, and growth. European Economic Review. Vol. 56, p. 97-115.

Guest, R. S.; McDonald, I. M. (2007) Global GDP shares in the 21st century - An equilibrium approach. Economic Modelling. Vol. 24, p. 859-877.

Ha, J.; Lee, S. (2016). Demographic dividend and Asia's economic convergence towards the US. The Journal of Economics of Ageing. Vol. 8, p. 28-41.

Hasan, A. F. M.; Ruhul, S.; Bloch, H. (2011). Population age structure, saving, capital flows and the real exchange rate: a survey of the literature. Journal of Economic Surveys. Vol. 25, no 4, p. 708-736.

Hasan, M. S. (2010). The long-run relationship between population and per capita income growth in China. Journal of Policy Modeling. Vol 32, p. 355-372.

Heijdra, B. J.; Romp, W. E. (2009). Retirement, pensions, and ageing. Journal of Public Economics. Vol. 93, p. 586-604.

Higgins, M. (1998). Demography, national savings, and international capital flows. International Economic Review. Vol. 39, no. 2, p. 343-369.

Hondroyiannis, G.; Papapetrou, E. (2000). Do demographic changes affect fiscal developments? Public Finance Review. Vol. 28, no. 5 p. 468-488.

Yang, C. (2014). Demographic Transition and Labour Market Changes: Implications for Economic Development in China. Journal of Economic Surveys. Vol. 28, no. 4, p. 617-635.

Jaimovich, N.; Siu, H. E. (2009). The Young, the Old, and the Restless: Demographics and Business Cycle Volatility. American Economic Review. Vol. 99, no. 3, p. 804-826.

Katz, S. (2000). Busy bodies: Activity, aging, and the management of everyday life. Journal of Aging Studies. Vol. 14, no. 2, p. 135-152.

Kenc,. T.; Sayan, S. (2001). Demographic shock transmission from large to small countries An overlapping generations CGE analysis. Journal of Policy Modeling. Vol. 23. p. 677-702.

Kinsella, K.; Phillips, D. R. (2005). Global Aging: The challenge of success. Population Bulletin. Vol. 60, no. 1, p. 3-40.

Kohler, H. P.; Billari, F. C.; Ortega, J. A. (2002). The emergence of lowest-low fertility in Europe during the 1990s. Population and development review. Vol. 28, no. 4, p. 641-680. 
Krueger, D.; Fernandez-Villaverde, J. (2007). Consumption over the Life Cycle: Facts from Consumer Expenditure Survey Data. The Review of Economics and Statistics. Vol. 89, no. 3, p. 552-565.

Life expectancy at birth, total (years). [online] World Bank. Available at: http://data.worldbank.org/indicator/SP.DYN.LE00.IN [Accessed 20 Apr. 2017]

Life expectancy by age and sex. [online] Eurostat. Available at: http://appsso.eurostat.ec.europa.eu/nui/show.do?dataset=demo_mlexpec\&lang=en [Accessed 11 Jan. 2016]

Lindh, T.; Malmberg, B. (2009) European Union economic growth and the age structure of the population. Economic Change and Restructuring. Vol 42, no. 3, p. 159-187.

Macunovich, D. J. (2012). The role of demographics in precipitating economic downturns. Journal of Population Economics. Vol 25, no. 3, p. 783-807

Mankiw, N. G.; Weil, D. N. (1989). The Baby Boom, the Baby Bust, and the Housing Market. Regional Science and Urban Economics. Vol. 19, p. 235-258.

Marattin, L.; Salotti, S. (2011). Productivity and per capita GDP growth: The role of the forgotten factors. Economic Modelling. Vol 28, p. 1219-1225.

Merette, M.; Georges, P. (2010). Demographic changes and the gains from globalisation: An analysis of ageing, capital flows, and international trade. Global Economy Journal. Vol 10, no. 3, p. 1-39

Modigliani, F. (1966). The Life Cycle Hypothesis of Saving, the Demand for Wealth and the Supply of Capital. Social Research. Vol. 33, no. 2, p. 161-217.

Muysken, J.; Ziesemer, H., T. (2013). A permanent effect of temporary immigration on economic growth. Applied Economics. Vol. 45, p. 4050-4059.

Nationla accounts aggregates by industry. [online] Eurostat. Available at: http://appsso.eurostat.ec.europa.eu/nui/show.do?dataset=nama_10_a64\&lang=en [Accessed 12 Jan. 2016]

Ohtake, F.; Saito, M. (1998). Population aging and consumption inequality in Japan. Review of Income and Wealth. Vol. 44, no. 3, p. 361-381.

Oliver, M. (2015). Population ageing and economic growth in Japan. International Journal of Sociology and Social Policy. Vol, 35, no. 11-12, p 841-863.

Plumper, T.; Troeger, V. E.; Manow, P. (2005). Panel data analysis in comparative politics: Linking method to theory. European Journal of Political Research. Vol, 44, p. 327-354.

Population on 1 January by age group and sex. [online] Eurostat. Available at: http://appsso.eurostat.ec.europa.eu/nui/show.do?dataset=demo_pjangroup\&lang=en [Accessed 20 Jan. 2016]

Poterba, J., M. (2001) Demographic Structure and Asset Returns. The Review of Economics and Statistics. Vol. 83, no. 4, p. 565-584.

Pryor, F. L. (2003). Demographic effects on personal saving in the future. Southern Economic Journal. Vol 69, no. 3, p. 541-559.

Razin, A.; Sadka, E. (2007). Aging population: The complex effect of fiscal leakages on the politicoeconomic equilibrium. European Journal of Political Economy. Vol. 23, p. 564-575.

Rojas, J. A. (2005). Life-cycle earnings, cohort size effects and social security: a quantitative exploration. Journal of Public Economics. Vol. 89, p. 465-485.

Rowthorn, R. (2008). The fiscal impact of immigration on the advanced economies. Oxford Review of Economic Policy. Vol. 24, no. 3, p. 561-581.

Settersten Jr. R. A.; Mayer, K. U. (1997). The measurement of age, age structuring, and the life course. Annual Review of Sociology. Vol. 23, p. 233-261.

Silivertovs, B.; Kholodilin, K., A.; Thiessen, U. (2011). Does aging influence structural change? Evidence from panel data. Economic Systems. Vol. 35, p. 244-260.

Smrčka, L.; Arltova, M. (2012). Economic aspects of population ageing in developed countries. PolitickaEkonomie. Vol. 60, no. 1, p. 113-132.

Tabata, K. (2005). Population ageing, the costs of health care for the elderly and growth. Journal of Macroeconomics. Vol. 27, p. 472-493.

Tyers, R.; Shi, Q. (2007). Demographic Change and Policy Responses: Implications for the Global Economy. The World Economy. Vol. 30, no. 4, p. 537-566. 
Zimmermann, K. F. (2005). European labour mobility: Challenges and potentials. Economist. Vol 153, no. 4 , p. $425-450$. 